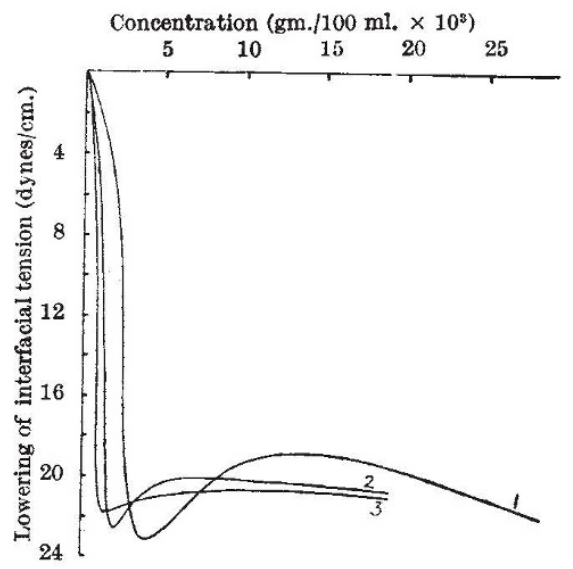

FIg. 2. INFLUENCE OF VARYING INTERFAOIAL AGE ON THEE TENSIONCONOENTRATION FOR THE SYSTEM CYCLOHEX ANE-WATER-METHYYLCELLULLOSE.

$$
\begin{aligned}
& \text { 1, interfacial age, } 1 \text { min. } \\
& 2 \text {, oldešt interfaces min. }
\end{aligned}
$$

Thus, one is led to conclude that minima in tension - concentration curves owe their existence solely to the use of tension data for surfaces or interfaces which are in differing states of rearrangement, and that if precautions are taken to make measurements on completely equili

brated surfaces or interfaces, this disturbing 'anomaly' will disappear.
Full details of this work will be published elsewhere.

The Beacon,

Sandon Road,

Chester.

Nov. 23.

1 Matthews, J. B., Ph.D. Thesis, Liverpool (1939)

Matthews, J. B., Trans. Faraday Soc., 35, 1113 (1939).

Addison, C. C. Nature, 156, 600 (1945).

Areas, J. M.', Hauser, E. A., and Tucker, W. B., J. Phys. Chem.

42, 1001 (1938)
'Miles, G. D., and Shedlovsky, L., J. Phys. Chem., 48, 57 (1944).

\section{Molecular Weight Distribution of Proteins}

THE recent publication ${ }^{1}$ of an examination of Svedberg's theory of molecular weight distribution, in which the theory is considered to be invalid, suggests that a treatment, similar in some of its details, might be of interest. This was prepared in $1944^{2}$, and the conclusion agree with those of Johnston, Longuet-Higgins and Ogston ${ }^{1}$, and with those of Bulls. It seemed clear that the explanation of the imperfection of his theory given by Svedberg ${ }^{4}$, namely, that the mean molecular weights of the amino-acid residues in the different proteins were not the same, is inadequate, since, for example, the mean residue weights of zein and ovalbumin are in a ratio not far different from $1: 1 \cdot 1$ while the molecular weights of the proteins themselves are in a ratio of approximately $1: 1 \cdot 3$. Moreover, the arbitrary omission of gliadin hordein and two hæmocyanins from Svedberg's classiflication needs a better reason than the maintenance of his hypothesis. Further, the existence of proteins of lower molecular weights than the basic unit of 17,600 (such as ribonuclease and cytochrome-? at 13,000 ) is a serious complication to the theory, and there are certain groups, such as Svedberg's ' $\times 96$ ' group, where the actual mean of the molecular weights cited is not even approximately that of the characteristic 'group value'.

The method of analysis adopted was this: (1) to divide the molecular weight given by Svedberg by his figure of 17,600 , correcting his values for eytochrome-c and ovalbumin and adding the flgure for ribonuclease; (2) to work out the geometrical mean of these ratios, and quote it as a logarithm against the logarithm of Svedberg's group number; (3) to obtain the actual standard dov

$$
\sigma=\sqrt{\frac{\Sigma \Delta^{2}}{(n-1)}} ; . . . .
$$

(4) to obtain a value for the standard deviation of random distribution, assuming that if the values of successive Svedberg group numbers are $A, B$ and $C$, the boundaries of group $B$ can be flxed at $a=\sqrt{ }(A B)$ and $b=\sqrt{ }(B C)$. The random series is obtained by taking the geometrical progression, $a$, $a r$, $a r^{2}, \ldots a r^{n}=b$, in the limiting case when $r \rightarrow 1$ and $n \rightarrow \infty$. The logarithm of the geometrical mean is
then $\frac{1}{2} \log a b$. This random standard deviation will then conform to the formula:

$$
\sigma_{r}=\frac{\log b / a}{2 \sqrt{ } 3}
$$

\begin{tabular}{|c|c|c|c|c|c|c|}
\hline $\begin{array}{l}\text { Svedberg } \\
\text { group } \\
\text { number }\end{array}$ & $\begin{array}{l}\log _{13} \\
\text { group } \\
\text { number }\end{array}$ & $\begin{array}{l}\log _{10} \\
\text { geom. } \\
\text { mean }\end{array}$ & $\begin{array}{l}\text { Svedberg } \\
\text { standard } \\
\text { deviation }\end{array}$ & $\begin{array}{c}\text { Random } \\
\text { mean } \\
\text { value }\end{array}$ & $\begin{array}{l}\text { Random } \\
\text { standard } \\
\text { deviation }\end{array}$ & $\sigma / \sigma_{r}$ \\
\hline $\begin{array}{r}1 \\
2 \\
4 \\
6 \\
8 \\
16 \\
24 \\
48 \\
96 \\
192\end{array}$ & $\begin{array}{l}0 \cdot 000 \\
0 \cdot 301 \\
0 \cdot 602 \\
0 \cdot 778 \\
0.903 \\
1.204 \\
1 \cdot 380 \\
1 \cdot 681 \\
1.982 \\
2 \cdot 281\end{array}$ & $\begin{array}{l}\overline{1}: 995 \\
0 \cdot 312 \\
0 \cdot 598 \\
0 \cdot 772 \\
0 \cdot 969 \\
1 \cdot 229 \\
1 \cdot 397 \\
1 \cdot 670 \\
1 \cdot 917 \\
2 \cdot 245\end{array}$ & $\begin{array}{l}0.084 \\
0.054 \\
0.044 \\
0.052 \\
0.105 \\
0.058 \\
0.051 \\
0.029 \\
0.106 \\
0.051\end{array}$ & $\begin{array}{l}0.301 \\
0 \cdot 571 \\
0 \cdot 765 \\
0.948 \\
1.173 \\
1.411 \\
1.881 \\
1.982 \\
2 \cdot 281\end{array}$ & $\begin{array}{l}0 . \overrightarrow{100} \\
0.071 \\
0.045 \\
0.063 \\
0.071 \\
0.116 \\
0.100 \\
0.100 \\
0.100\end{array}$ & $\begin{array}{l}0.54 \\
0.62 \\
1.15 \\
1.67 \\
0.82 \\
0.44 \\
0.29 \\
1.06 \\
0.51\end{array}$ \\
\hline
\end{tabular}

No lower limit could be assigned to the flrst group, for which no random devistion is therefore quoted.
The results of this analysis are shown in the accompanying table. It is seen that in three of the groups $(6,8$ and 96$)$ the 'Svedberg devistion' is actually greater than the random flgure, while in all the others it is so great in comparison with the latter that the disturbing factors which account for the divergence must be excessively large.
Certainly the Svedberg hypothesis does not survive this investigstion.

Huntington, York.

1 Johnston, Longuet-Higgins and Ogston, Trans. Faraday Soc., 588 (1945).

2D.Phil. Dissertation, accepted March 1944.

"Sull, "Advances in Enzymology", 1 (1941).

\section{Migration of Acyl Groups from Side-chain Nitrogen to Nuclear Carbon}

THE Claisen and Fries rearrangements embody the migrations of alkyl and acyl groups respectively, from oxygen of the side-chain to carbon of the position of oxyl but the movement of acyl groups from side-chain nitrogen (parallel to the Fries reaction in the phenol system) is not so well known. The work which has been done in this direction is mostly fragmentary, but it has led to the conclusion that migration can occur in the diacyl anilines. Writh monoacyl anllines migration is more difficult to bring about and, apart from an unconfirmed claim by H. Meyer and Hormann", it was not until recently that the rearrangement of acetanilide was established. By heating a melt of the anilide with aluminium chloride, Kursanov ${ }^{3}$ obtained a 12 per cent yield of $p$-aminoacetophenone, and about the same time a similar observation was made by us, although we obtained a somewhat larger vield of the $p$ aminoketone and also identiffed the $o$-amino isomeride as a product. We have now obtained a similar result with propionanilide, and the investigation is being extended to further monoacylated amines. J. F. J. DIPPY. WOoD.

South-East Essex Technical College,

Dagenham.
Mining and Technical College, Wigan.
Nov. 12 .

1 Notably Chattaway, J. Chem. Soc., 85, 386 (1904).

Monats., 36, 707 (1915). 286 (1943).

Hydrogen Overvoltage as a Factor in the Corrosion of Metallic Couples

IN their communication under the above heading, Messrs. Le Brocq and Cockg $^{1}$ redirect attention to a point that has been too often overlooked: namely, that the effectiveness of a metal as the cathode in a bimetallic corrosion system where hydrogen is evolved is dependent more upon the hydrogen overvoltage characteristics of the metal than upon its equilibrium single-potential in the electromotive series.

I have illustrated the general relationships between the cathodic and anodic potentials and the corrosion currents in bimetallic systems by a graphical method of potential/current diagrams ${ }^{2}$, which is an extension of the method originally given by Evans ${ }^{3}$, and used with modiflcations by Pourbaix $x^{4}$ and by Wagner and Traud ${ }^{5}$, for a single corroding metal. The special case cited by Messrs. The Broca snd Cocks-the small acceleration of magnesium corrosion caused by contact with mercury, and the relatively considerable acceleration contact with mercury, and the relatively considerable acceleration caused by contact with zinc-may be illustrated by the method ss in Figs. 1 and 2. In Fig. 1 , the lines $C \mathrm{Mg}$ and $A \mathrm{Mg}$ are the respective polarization curves of the cathodes and anodes on magnesium; they show the change of hydrogen overvoltage (assuming that the only cathodic reaction is hydrogen discharge), and the change in potentia of the anode, with the current passing. If we neglect electrolytic and metalife resistance, the point of intersection of the curves, $P$, represents the corrosion current, $i$, and the corrosion potential of the magnesium. When a mercury cathode is coupled to the magnesium, if we assume that to a flrst approximation the system is equipotential, the small curve $C$ Hg, for a high-overvoltage cathode) may be added to that on the magnesium to give the total cathodic current at any potential curve $C$ ( is now represented by $i^{\prime}$, and for a steep CHg curve, it is only slightly 